\title{
Hallazgo de divertículo duodenal en un perro de raza Bóxer. Reporte de un caso
}

\author{
Finding of a duodenal diverticulum in a Boxer \\ breed dog. Report of a case
}

\section{Descoberta de um divertículo duodenal em um cão da raça Boxer. Relato de um caso}

\author{
Ruiz Sabella $T^{1}$, Diaz $M^{1}$ \\ 1 Universidad de Buenos Aires, Facultad de Ciencias Veterinarias, Cátedra de Cirugía. Chorroarin 280. \\ Ciudad Autónoma de Buenos Aires
}

Correo electrónico: tadeo.ruizsabella@gmail.com

Fecha de recepción:28/09/2021

Fecha aceptación para su publicación: 20/11/2021

\section{RESUMEN}

Los divertículos intestinales son muy frecuentes en medicina humana, siendo la ubicación más común en el colon (35-75\%) y duodeno (15-42\%). En medicina veterinaria son poco comunes. El presente reporte tiene por objetivo describir la presencia de un divertículo duodenal en un canino de raza Bóxer, de $25 \mathrm{~kg}$ de peso, pelaje bayo, de dos años de edad, cuya historia reflejaba vómitos esporádicos, pérdida de peso e hiporexia. Sometido a laparotomía exploratoria por presencia de cuerpo extraño en duodeno descendente, el paciente presentó in-situ, una deformación compatible con divertículos, hallándose como resultado histopatológico la confirmación del mismo. Ante la presencia de signos gastrointestinales en caninos, jóvenes en general y 
de raza Bóxer en particular, se sugiere considerar al divertículo intestinal como entidad patológica, dentro de los diagnósticos diferenciales.

Palabras Clave: caninos, bóxer, divertículo duodenal, vómitos esporádicos, pérdida de peso

\section{ABSTRACT}

Intestinal diverticula are very common in human medicine, being the most common location in the colon (35-75\%) and duodenum (15$42 \%)$. In veterinary medicine they are rare. The present report aims to describe the presence of a duodenal diverticulum in a Boxer breed canine, weighing $25 \mathrm{~kg}$, with brown fur, two years old, whose history reflected sporadic vomiting, weight loss and hyporexia. Undergoing exploratory laparotomy due to the presence of a foreign body in the descending duodenum, the patient presented in situ, a deformation compatible with diverticula, with confirmation of it as histopathological result. Given the presence of gastrointestinal signs in canines, young people in general and Boxer breed in particular, it is suggested to consider the intestinal diverticulum as a pathological entity, within the differential diagnoses.

Key Words: canines, boxer, duodenal diverticulum, sporadic vomiting, weightloss

\section{RESUMO}

Os divertículos intestinais são muito comuns na medicina humana, sendo a localização mais comum no cólon (35-75\%) e duodeno (15$42 \%$ ). Na medicina veterinária, são raros. 0 presente relato tem como objetivo descrever a presença de divertículo duodenal em um canino da raça Boxer, de $25 \mathrm{~kg}$, com pelo marrom, de dois anos, cuja história refletia vômitos esporádicos, emagrecimento e hiporexia. Submetida a laparotomia exploradora devido à presença de corpo estranho em duodeno descendente, a paciente apresentou in situ, deformação compatível com divertículos, sendo confirmada como resultado histopatológico. Dada a presença de sinais gastrointestinais em caninos, jovens em geral e na raça Boxer em particular, sugere-se considerar o divertículo intestinal como entidade patológica, dentro dos diagnósticos diferenciais.

Palavras-chave: caninos, bóxer, divertículo duodenal, vômito esporádico, perda de peso 


\section{Introducción}

Los divertículos intestinales son anomalías que dan lugar a la formación de dilataciones de la pared de los intestinos. Los divertículos intestinales son muy frecuentes en medicina humana ${ }^{(1)}$, siendo la ubicación más común en el colon, seguida del duodeno ${ }^{(2)}$. Los divertículos del intestino delgado fueron descritos originalmente por el padre de la cirugía alemana, Guilhelmus Fabricius Hildanus en 1598. Pero no fue hasta el año 1809 que el anatomista alemán Johann Friedrich Meckel clasificó los mismos y describió las bases embriológicas del divertículo que lleva su nombre, demostrando que este divertículo es resultado de la atrofia incompleta del conducto onfalomesentérico o vitelino ${ }^{(1)}$ El divertículo de Meckel es la anomalía congénita encontrada con más frecuencia en patología del sistema digestivo, y afecta más comúnmente al íleon. La diferencia entre divertículo intestinal y divertículo intestinal Meckel es, por tanto, la ausencia de comunicación con la luz intestinal en el caso del divertículo de Meckel y la presencia, en la mayoría de las personas, de tejido ectópico de mucosa gástrica. Y ha sido utilizado indiscriminadamente para denominar cualquier divertículo en cualquiera de las porciones el tracto gastrointestinal. ${ }^{(3,4)}$ Así mismo, los divertículos duodenales, en medicina humana, son el segundo sitio más frecuente de los divertículos en el tubo digestivo después del colon y seguido del yeyuno.

Los divertículos duodenales se localizan en un 10 a $67 \%$ en la segunda porción del duodeno, siendo raros en tercera y cuarta ${ }^{(2,5)} \mathrm{Se}$ pueden clasificar como verdaderos, cuando están involucradas todas las capas intestinales; y falsos o speudo-diverticulos cuando solo está involucrada la capa mucosa y submucosa. También se pueden clasificar como intraluminales y extraluminales según si la herniación de la mucosa y submucosa a través de un defecto de la capa muscular es hacia adentro o hacia afuera respectivamente. Por último se los puede clasificar como congénitos o adquiridos ${ }^{(4,1)}$ En medicina veterinaria los divertículos duodenales son poco comunes y solo unos pocos casos fueron reportados. La mayoría son en perros de raza Bóxer, con una incidencia de uno cada dos casos reportados. La mayoría de los casos son hallazgos, tanto en medicina humana como veterinaria, siendo que no presentan sintomatología previa. Cuando lo hacen, presentan anemia y hemorragia digestiva alta, secundaria a ulceración digestiva en el divertículo duodenal. ${ }^{(3,4)}$ El objetivo del presente estudio es el reporte de un caso clínico de divertículo duodenal en un canino de raza Bóxer, el cual se halló durante una laparotomía exploratoria por un caso de obstrucción intestinal por cuerpo extraño. 


\section{Presentación del caso}

Se presentó a consulta un canino macho de raza Bóxer, de tamaño mediano, cuyo peso fue de $25 \mathrm{~kg}$, color bayo con pecho blanco, de 2 años de edad. Como motivo de consulta se describe que los tenedores responsables lo notaron más flaco y con hiporexia. Adicionalmente notaron que presentaba vómitos esporádicos de pasto y alimento, presentaba episodios de tos y secreción lagañosa ocular. Previo a la consulta había sido desparasitado debido a que convivía con otro perro cuyo coproparasitológico arrojó positivo a Giardias.

$\mathrm{Al}$ examen objetivo general se observó la presencia de mucosas rosas pálidas, deshidratación de $5 \%$, normotermia y leve molestia a la palpación abdominal. Presentaba una condición corporal de 2/5.

Se tomó una muestra de sangre de vena safena externa para realizar hemograma y bioquímica sanguínea, cuyo resultado arrojó valores que se encontraban dentro de los parámetros normales. Asimismo se realizó una prueba de Ehrlichia canis (por inmunocromatografia) resultando negativa. Se realizó una ecografía abdominal donde se observó una marcada distensión gástrica con contenido mixto (alimento y gaseoso), a pesar de presentar ayuno de 12 horas previo al estudio. Adicionalmente, se observó una disminución marcada de la motilidad intestinal junto con la presencia de movimientos en vaivén y la presencia de un cuerpo extraño (CE) en duodeno descendente con signos obstructivos.

De acuerdo con estos hallazgos y conjuntamente con los signos clínicos, se indicó laparotomía exploratoria. Durante dicho procedimiento se observó distensión en el estómago y duodeno descendente con la presencia de un CE en el mismo. En la flexura duodenal caudal se observó la presencia de una dilatación en el borde anti-mesentérico de $4 \times 3 \mathrm{~cm}$, altamente vascularizada, procedente del omento que parecía cubrir al mismo. Dicha dilatación impedía el pasaje del CE debido a su ubicación. Se realizó enterotomía para retirar el CE descripto por imágenes, resultando ser un carozo de mango de $3 \mathrm{~cm}$ de ancho por 7 cm de largo: Se realizó una biopsia de espesor completo de la pared del divertículo. La evolución postquirúrgica del paciente, fue favorable.

El resultado histopatológico demostró que la arquitectura tisular de la muestra se encuentra conservada, no presentando alteraciones relevantes en mucosa, submucosa, muscular y serosa del fragmento del intestino delgado remitido En los controles post quirúrgicos el paciente presentó un aumento de peso y no presentó signos gastrointestinales. 


\section{Discusión}

En medicina veterinaria son muy pocos los casos reportados de divertículos duodenales. En dichos reportes parecería que estas lesiones son más frecuentes en caninos de raza Bóxer. Así como también el tipo de divertículo más común el congénito. ${ }^{(3,2,6)}$ La sintomatología que se describe está representada principalmente por vómitos, diarreas, anemia, hemorragias gastrointestinales, y sincopes cuando existen anemias severas. ${ }^{(2,4)}$ Sin embargo, algunos casos no presentaron sintomatología asociada al divertículo como el caso reportado en este trabajo, sino la típica sintomatología de obstrucción parcial por cuerpo extraño. ${ }^{(3)}$ La ecografía realizada no demuestra la presencia del divertículo, tampoco se han encontrado reportes de diagnóstico exclusivo por ultrasonografía, sino de diagnósticos combinados con radiografías contrastadas con bario y endoscopia. En otros casos el diagnostico fue por hallazgo en una laparotomía exploratoria por obstrucción por cuerpo extraño. ${ }^{(3,6)}$ Si bien la resección del divertículo duodenal con anastomosis termino-terminal es el tratamiento indicado para estos casos, el hallazgo durante la cirugía de una patología desconocida, hicieron que no se realizara la misma y se optara por la biopsia de la pared duodenal. ${ }^{(3,2,4)}$ La histopatología nos permitió clasificar la lesión como un divertículo duodenal verdadero ya que están involucradas todas las capas del duodeno, y nos permitió clasificarla también como congénito por la edad temprana del paciente. Asimismo, extrapolando el término de medicina humana, podemos decir que no es un divertículo de Meckel por la definición ya expresada. Aunque ha sido informado en caballos, 7 cerdos, 8 bovinos, y 9 ratas, son muy raros en carnívoros. ${ }^{(6)}$ En conclusión, ante la presencia de signos gastrointestinales en caninos jóvenes, particularmente de raza Bóxer, deberíamos considerar al divertículo intestinal dentro de los diagnósticos diferenciales. 


\section{Bibliografía}

1. Kassir R, Boueil-Bourlier A, Baccot S, Abboud K, Dubois J, Petcu C. et al. Jejunoileal diverticulitis: Etiopathogenicity, diagnosis and management. Int J Surg Case Rep. 2015; 10: 151-153. Published online 2015 Mar 26. doi: 10.1016/j.ijscr.2015.03.044

2. Lorigados C, Machado Zoppa A, Schiller A ,Tiburcio l, Giusti Calderón F, Pantano M. Partial Obstruction and Intestinal Bleeding Secondary to a Congenital Duodenal Diverticulum in a Dog. Acta Scientiae Veterinariae. 2021; Vol. 49, p1- 5.5p

3. Blesch $\mathrm{M}$, Livet $\mathrm{V}$, Cabon $\mathrm{Q}$ Cahon $\mathrm{T}$. Obstruction intestinale par un corps étranger au sein d'un diverticule duodénal chez un chiot Boxer. Revue de Médecine Vétérinaire.2016; Vol167 No.3/4 pp:71-76 ref.19.

4. Van Klaveren NJ, Grinwis GC, Broeks BAW, Kirpensteijn J. Collapse following gastrointestinal bleeding secondary to a congenital duodenal diverticulum in two littermate boxer pups. Journal of Small Animal Practice. 2008;49(02):103-106

5. Guardado-Bermúdez F, Ardisson-Zamora JF, Rojas-González JD, Medina-Benítez A, Fernando Corona-Suárez. Divertículo duodenal perforado. Reporte de caso y opciones de tratamiento. Cir Cir 2013;81:340-347.

6. Polf $\mathrm{H}$, Poteet B. Imaging diagnosis -duodenal diverticulum in a dog. Veterinary Radiology \& Ultrasound.2010. Doi: 10.1111/j.1740-8261.2009.01623. 